\title{
Antisymmetry and Hixkaryana*
}

Michael Barrie, Sogang University

\begin{abstract}
This paper proposes an analysis for the basic clause structure of Hixkaryana, an OVS language, within an Antisymmetric framework. There are two important contributions to the study of OVS languages and Antisymmetry contained herein. First, given the universal order, Specifier-Head-Complement, it is proposed the OVS order arises by smuggling the object across the subject by raising the VP containing the object across the subject. Second, I propose a new generalization of OVS languages that is captured by the Antisymmetric analysis put forward. Namely, I show that, while OXV is quite widespread in SOV languages, it is absent in OVS languages. This is because SOV languages allow significantly more freedom in object placement than do OVS languages since the object must remain sufficiently low in order to be fronted along with the VP. This asymmetry would remain mysterious under a symmetric framework.
\end{abstract}

keywords: Antisymmetry, Hixkaryana, OVS order, smuggling, headedness

\section{Introduction}

This paper is an examination of the properties of OVS languages and how Antisymmetry Theory (Kayne 1994) impinges on the analysis of OVS. I look principally at Hixkaryana, but also draw on some data from Urarina, another genetically unrelated OVS language. I examine whether a headedness macroparameter must be admitted in light of OVS order, or whether the properties of OVS languages in fact support an Antisymmetric view of syntax. Several 
questions arise from this line of inquiry. First, if OVS is the default word order, how does the object raise above the subject without violating some kind of Minimality constraint (in the sense of Rizzi 1990)? A directionality parameter (set to Complement-Head-Specifier, C-H-S) would account for OVS order is a straight-forward manner. Are there other properties of Hixkaryana and Urarina that suggest a C-H-S setting is on the right track, or are the predicted properties suspiciously absent? I will show that OVS languages impinge on Antisymmetry, and that the answers to these questions provide additional empirical support for this theory.

Antisymmetry not only imposes a strict algorithm on linearization. It also accounts for a number of otherwise puzzling asymmetries in word order universals (Kayne 2003). Some of these are alluded to briefly in section 3. In this vein, I note the following generalization, which emerges from the study of OVS languages. While SOV languages permit SOXV order (where $\mathrm{X}$ is any additional material such as an adverb or a PP), OVS languages do not permit OXVS order. This asymmetry is unexpected under a symmetric view of syntax, but, as I will see, receives a principled explanation under an Antisymmetric view of syntax.

The analysis of OVS order is summed up as follows. First, I show that Hixkaryana is an OV language (in the same way that Japanese is) and that the object raises to a position to the left of the verb within the VP complex. I then propose that OV order is derived in a manner similar to Kayne's analysis for postpostional phrases. Specifically, a ghost Agro'P attracts the object above the verb, giving rise to a VP shell with the order $\mathrm{O}-\mathrm{V}$. I also propose that the EPP in OVS languages is satisfied by VP rather than by DP (Massam 2001), thereby smuggling the object above the subject (Collins 2005). ${ }^{\mathrm{i}}$ The lack of OXVS is a result of the fact that the only way $\mathrm{O}$ can raise above $\mathrm{S}$ is for it to be smuggled together with $\mathrm{V}$, thereby removing the opportunity for $\mathrm{O}$ to scramble above any adjoined material. Furthermore, I show that word order in embedded clauses is accounted for by the current proposal. Embedded clauses in Hixkaryana are non-finite and display ergative syntax. I argue that the 
TP layer is absent in these nominalized clauses, accounting for the lack of nominative Case and the ergative properties in these constructions. Given the lack of a TP, we expect there to be no VP raising, predicting SOV order in embedded clauses - a prediction that is borne out.

Kayne's (1994) Antisymmetry theory proposes a strict relationship between

hierarchical structure and linear order which has yielded much fruitful research, leading to important generalizations (Aboh 2004; Bianchi 1999; Cinque 2005; Kayne 2003; Lee 2000). In particular, Kayne $(2003 ; 2009)$ showed that several properties of SOV fall into place under Antisymmetry. A large portion of the forthcoming discussion is devoted to arguments against headedness in general and against any analysis of Hixkaryana (and Urarina) that relies on a Headedness Parameter. In particular, I show that a right Specifier analysis has trouble dealing with left Specifier properties, such as clause-initial wh-phrases.

The remainder of this paper is structured as follows. Section 2 describes the general properties of Hixkaryana, touching on Urarina from time to time. Section 3 contains a brief discussion on headedness and Antisymmetry including a critique of some recent proposals on the return to a headedness approach to word order variation. Section 4 expands on some of the ideas in Kayne (2003) and presents the current proposal. Section 5 presents the analysis of the properties of OVS discussed in section 2. Section 6 is a brief conclusion.

\section{Properties of OVS}

As mentioned in above, the principal language that forms the empirical foundation of this study is Hixkaryana, a Carib language with about 500 speakers in Amazonas region of Brazil. I also discuss to a smaller extent Urarina, a language isolate, spoken in the Peruvian Amazon Basin). Obviously, one property of these languages I wish to capture is their basic OVS order. This order should be captured with ordinary A-movements and should not involve any special fronting mechanisms or A-bar positions associated with special interpretations, such 
as focus. The following examples illustrate OVS order in Hixkaryana (1) and Urarina (2). ${ }^{\text {ii }}$

Note that OVS order is found regardless of whether the object is nominal or clausal. ${ }^{\text {iii }}$

(1) a. b ryekomo y-otaha-no wos

boy AGR-hit-PST woman

'The woman hit the boy.' (Derbyshire, 1979, p. 38, ex (85a))

b. $\quad \mathrm{t}$ ton $\mathrm{r} \quad$ yokarymano

his-own-going he-told-it

'He told about his going.' (ibid, p. 22, ex (50))

c. toko om n yaka, kano wya

go your-house to, I-said-it to-him

““Go home,” I said to him.' (ibid, p. 3, ex (1a))

d. txetxa wawo wewe yomokoton $r$ wenyo

forest in tree falling.of I.saw.it

'I saw a tree falling in the forest.' (Derbyshire 1985, ex (49b))

e. Waraka-wya honkyo $\varnothing$-won $r \quad$ xe wehxana $^{\text {iv }}$

Waraka-by peccary shooting-of desire I.am

'I want Waraka to shoot peccary.' (ibid, (45g))

(2) a. nitoaneĩ hetau=te kat a lem $-\mathrm{e}=1 \quad$ lomaj

like.that $\quad$ HRS $=$ FOC sink-3.SG.E=REM Lomai 
edara ne-ĩ $\quad k$ r $-a=n e \quad$ kuj a

water.people be-PRT go-PL-3SG.D=SUB so.that

'Lomai sank the people like that so that they would become water people.'

(Olawsky 2006, p. 655, ex (936a))

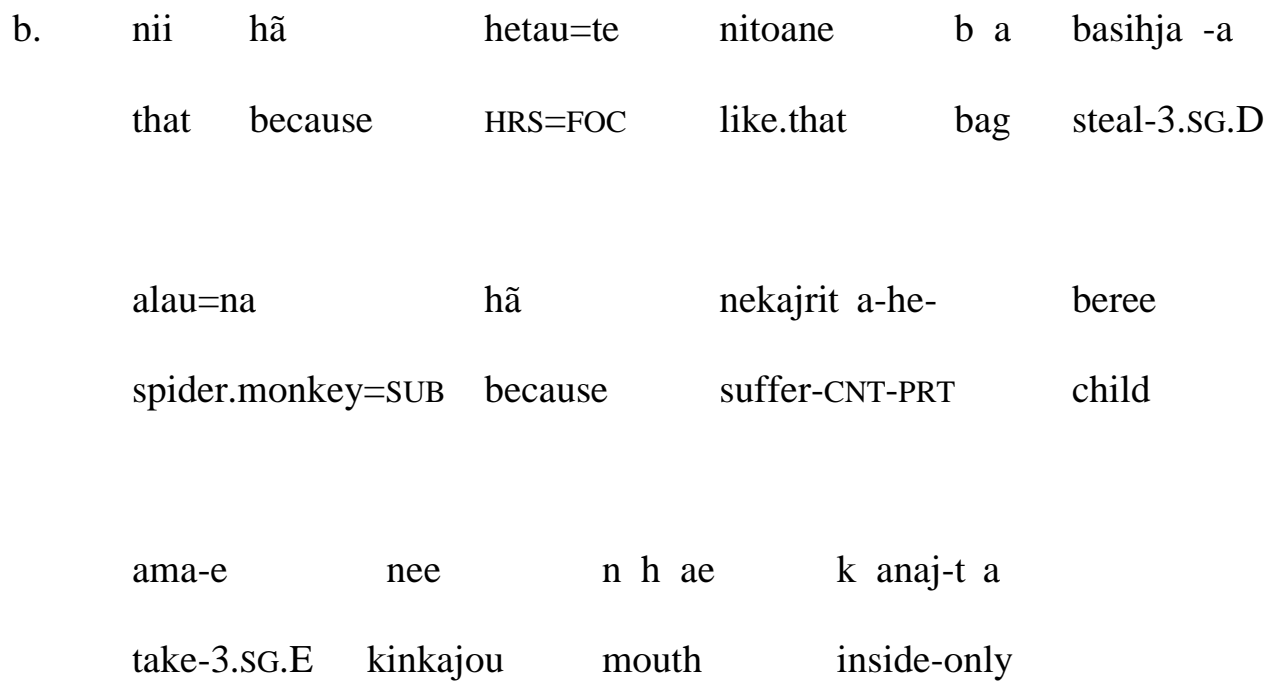

'Therefore, because the spider monkey stole kinkajou's bag like that, the kinkajou carries her children in her mouth, suffering.' (Olawsky 2006 p. 850, ex. (1183))

Kayne (2003) shows that while many VO languages disallow VXO (X an adverb or oblique of types), there is no OV language that uniformly disallows OXV (assuming $\mathrm{O}$ is definite). One immediate difference between OVS languages and the OV languages Kayne refers to is that OXV is not allowed. In other words, there is no OXVS. Hixkaryana has OVSX as its basic order (Derbyshire 1979: 40) and Urarina has XOVS and (to a lesser extent) OVSX as its basic order (Olawsky 2007). Furthermore, WALS notes three OVS languages 
for which the order among verb, object and oblique can reliably be found: Ungarinjin, Hixkaryana, and Päri. Ungarinjin and Päri pattern the same as Hixkaryana. That is, they have OVX order. Thus, an important generalization ${ }^{\mathrm{v}}$ which must be captured is the following:

\section{SOV $\rightarrow$ SOXV usually widespread OVS $\rightarrow \quad$ OXVS not found}

Note that the works cited for Hixkaryana and Urarina are descriptive grammars, which typically do not contain examples of ungrammatical sentences. Nevertheless, both authors clearly indicate that OXVS is not found in their respective languages.

"The basic order of the constituents [in Hixkaryana] is OVS, with indirect object and adjunct normally following the subject...Any element that normally follows the verb may be fronted to initial position in the sentence (preceding the direct object if there is one)..." (Derbyshire 1979: 40)

"The most typical position for any PP is before the main verb. In transitive clause with an overt $\mathrm{O}$ argument, the PP occurs before $\mathrm{O}$. There are almost no attested natural examples for their occurrence between $\mathrm{O}$ and the verb. One is cited in (958), where the postposition raj 'for' is cliticized with a possessive proclitic; the demonstrative which functions as the object, in turn, is realised as a proclitic attached to it ej 'for you'. Due to the clitic status of the elements involved, it is questionable whether this can be characterized as a PP-insertion between $\mathrm{O}$ and $\mathrm{V}$. Since this example is marginal at any rate, one could 
conclude that generally, PPs do not occur in this position." (Olawsky 2006:

670)

Like other OV languages Hixkaryana, (4)a, and Urarina, (4)b, both exhibit postpositions.

(4)

a. t tonye ohsamnohtoho kom yaka

let.us.go meeting.place COLL to

Let's go to their meeting place. (Derbyshire 1979, p. 24)

b. nii banaao asae

that shelter under

under that leaf-shelter (Olawsky 2006, p. 225, ex (334b))

Questions in Hixkaryana obligatorily front $w h$-phrases. Hixkaryana also exhibits topicalization, which fronts the topicalized phrase to the left edge of the clause (Derbyshire 1977, 1979, 1985).

a. onok tho yonyetxkon kamara who DEVLD he.was.eating.them jaguar

'Whom did the jaguar used to eat?' (Derbyshire 1979: 8, ex (16b))

b. onok b ryekomo komo yonyetxkon

who child COLL he.was.eating.them

'Who used to eat children?' (Derbyshire 1979: 8, ex (16c)) 
$\begin{aligned} & \text { c. onok wya } \text { woto m mno } \\ & \text { who to meat you.gave.it }\end{aligned}$

‘To whom did you give the meat?' (Derbyshire 1979: 11, ex (22aii))

d. Waraka yawaka yoheko rohyaka oroke

Waraka axe he.sent.it to.me yesterday

'(It was) Waraka (who) sent the axe to me yesterday.' (Derbyshire 1977, 4b)

Similarly, focused XPs in Urarina move to the front of the clause (Olawsky 2006, 2007).

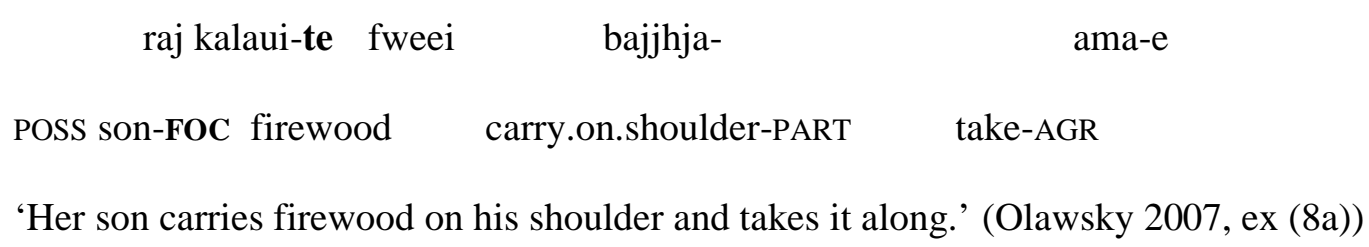

Finally, I discuss word order in embedded clauses in OVS. In Hixkaryana, finite embedded clauses exist only as direct quotes under verbs of saying, while all other forms of embedded clauses are nominalized and, hence, non-finite. ${ }^{\mathrm{vi}}$ Word order in nominalized clauses is SOV and display ergative syntax, while matrix clauses display nominativeaccusative syntax. ${ }^{\text {vii }}$ Consider the following examples (Derbyshire 1979 ex. (60a,e)). The subject of an intransitive and the object of a transitive appear are marked with agreement on the nominalized verbal complex. ${ }^{\text {vii }}$ The subject of a transitive appears in a by-phrase and does not trigger agreement on the verb. 
my-hunting-NZLR-when peccary I.shot.it.IMPST

'When I went hunting, I shot a peccary.'

(8)

ro-wya Kaywana $\quad$ Ø-yaryma-txhe, k kowonteko

me-by Kaywana him-throwing-after I.yell.IMPST

'After I threw Kaywana, I cried out loudly.'

(9)

$\begin{array}{llll}\text { kokaht mno } & \text { ro-wya } & \text { kamara } & \text { yo-nye-toko } \\ \text { I.ran.away } & \text { by-me } & \text { jaguar } & \text { AGR-seeing.of-when }\end{array}$

'I ran away when I saw the jaguar.'

(10) totke rmahaxa natxhe totokomo, Waraka way honyko won $r$ ke.

totke rmahaxa natxhe totokomo,

having.meat very much they.are people

Waraka wya honyko won $\mathbf{r}$ ke

Waraka by peccary shooting.of because

'The people have a lot of meat because Waraka shot peccary.'

(11) Manaus hona Waraka ton $\mathbf{r}$ xe wehxaha

Manaus to Waraka his.going desire I.am

'I want Waraka to go to Manaus.' (Derbyshire 1979, p. 72, ex. (72c))

In Urarina, OVS order is still found in embedded finite clauses (Olawsky 2007: 48).

This is shown in the following example and in example (2)b above. Unlike the nominalized 
embedded clauses in Hixkaryana, embedded clauses in Urarina still exhibit a nominativeaccusative pattern. These clauses are typically some kind of adjunct to the main clause

$$
\begin{aligned}
& \text { nee b a basihja }-\mathrm{a} \quad \text { alau=ne } \\
& \text { kinkajou bag steal-3SG.D spider.monkey=SUB } \\
& \text { 'When the spider monkey stole kinkajou's bag.' }
\end{aligned}
$$

Object complement clauses in Urarina are of two types (Olawsky 2006: 758). The first type appear with the suffix /-na/. These clauses are either non-finite or nominalized, and there is an obligatory same subject restriction between the main and the dependent clauses. Consider the following examples.

$$
\text { a. it a-na naj a-a }
$$

do-INF finish-3.SG.A

'He finished doing it.' (Olawsky 2006, p. 764, ex (1066a))

\section{b. si ra ha-naa $n$ n eti-a \\ bag make-INF begin.3.SG.E}

'She has begun to make the bags.' (ibid, ex (1066b))

The second type of object clause appears with the suffix (or clitic)/-ne/. These clauses may have a different subject (sometimes obligatorily), and are typically finite. Although Olawsky reports that object clauses must appear pre-verbally, he does give one example of a postverbal finite object clause. ${ }^{\text {ix }}$ Consider the following examples, where the subjects are obligatorily counter-indexed in the first example and co-indexed in the second example. 
a. $\quad \mathbf{t} \mathbf{r}-\mathbf{a}=\mathbf{n e} \quad$ heri-ji

arrive-3.SG=SUB want-NEG.3.SG

'He $\mathrm{e}^{1}$ does not want him ${ }^{* 1 / 2}$ to come.' (Olawsky 2006, p. 767, ex (1069b))

b. ruru=te naj e-re $\quad \mathbf{k}$ raanaa ni$a=n e=r a$

howler.monkey=FOC be.able-IRR.3.SG.E chief be-3.SG.D $=\mathrm{CND}=\mathrm{EMF}$

'The howler monkey could not be chief.' (ibid, ex (1070))

To conclude, both Hixkaryana and Urarina exhibit OVS as the most natural word order. Both languages have post-positions and also have A-bar fronting movement to a position in the left periphery. These two languages differ, however, in the syntactic properties of embedded clauses. Embedded clauses in Hixkaryana are obligatorily non-finite (and nominalized) and exhibit SOV order, while embedded clauses in Urarina can be finite and exhibit OVS order. Non-finite object clauses in Hixkaryana and in Urarina both appear in canonical object position; however finite object clauses in Urarina appear to be able to appear post-verbally. Crucially, both languages prohibit OXVS order. I now move to a discussion of the theoretical background of this study.

\section{Theoretical Background}

Theories of word order have traditionally piggy-backed off phrase-structural models of syntax, originally designed to capture constituency effects. Notably, the Headedness Parameter (Stowell 1981; Travis 1984) proposes that word order is encoded directly in the phrase structure and makes use of relationships such as "to the left" and "to the right." 
Arguments against headedness are found in Kayne (1994; 2003), so I confine my remarks here to a brief summary. Recently, however, M. Richards (2008) has presented new arguments in favour of headedness. I review this proposal in more detail in section 3.1 and provide more substantial commentary.

Antisymmetry proposes that linear order is not encoded directly in phrase structure but rather linear order is a byproduct of asymmetric c-command relations. I assume here a basic familiarity with Antisymmetry, but do introduce relevant aspects in section 3.2, along with a discussion on how Antisymmetry impinges on typological properties of word order.

\subsection{Antisymmetry}

This section briefly introduces those aspects of Antisymmetry that are important to the current study. I assume a basic familiarity with the concepts and keep the discussion necessarily brief. The reader is encouraged to consult Kayne (1994) for an in depth discussion. ${ }^{\mathrm{x}}$

The basic premise of Antisymmetry is tightly grounded in the Linear Correspondence Axiom (LCA), stated here.

$$
\text { LCA: } d(\mathrm{~A}) \text { is a linear ordering of } \mathrm{T} \text {. }
$$

$d$ is a function that maps a category to the set of terminals that it dominates. A is the set of ordered pairs of categories, $\langle\mathrm{X}, \mathrm{Y}\rangle$ such that $\mathrm{X}$ c-commands $\mathrm{Y}$. $\mathrm{T}$ is the set of all terminals. C-command is defined by category rather than by first branching node (see also May 1985). Thus, a specifier c-commands both the head of its projection and the complement, and therefore is linearized to the left of both. Furthermore, the head asymmetrically c-commands the material inside the complement (though not the complement itself) and is linearized to the left of the material inside the complement. This gives rise to Spec-Head-Complement order. 
As a further consequence of AS, there can be no multiple specifiers, no rightward movement, and no right adjunction.

Aside from stipulating the basic order of all XP's (namely S-H-C), the LCA captures various asymmetric typological properties of language, as described in Kayne (2003), such as the presence of verb-second and the absence of 'verb-second-to-last' and the rigid ordering found in serial verb constructions. As mentioned above, I also capture the lack of OXVS order.

Embedded clauses and complementizers play an important role in Kayne (2003). Following Rosenbaum (1967), Kayne suggests that IP cannot be directly selected by $\mathrm{V}^{0}$ unless it is first nominalized in some way. For finite clauses in English, he argues for the following derivation.

$$
\text { CP }
$$
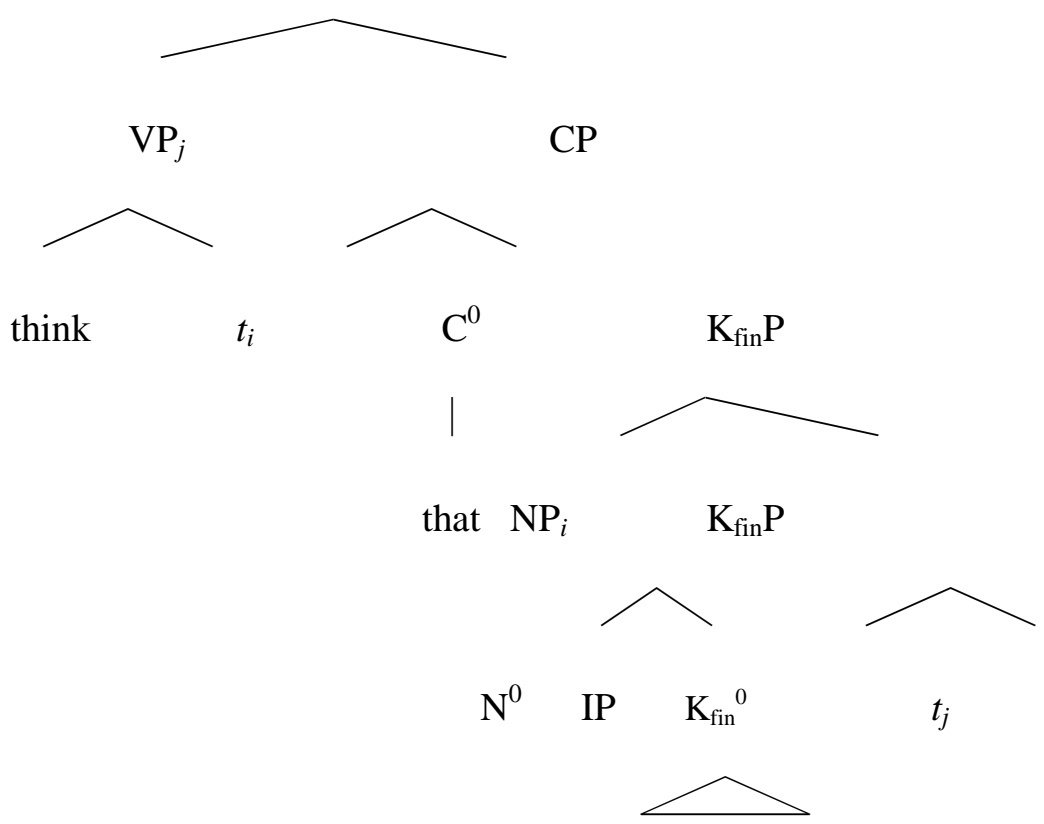

they're smart 
Later (his ex. 57), however, he conjectures that C-initial clauses are universally N-C-IP based partly on examples such as John mentioned (the fact) that Mary was away. This is clearly at odds with the derivation in (16) he proposes. Furthermore, the role of $\mathrm{K}_{\mathrm{fin}}{ }^{0}$ is unclear. Kayne suggests it can be assimilated to one of the Rizzian split CP categories; however, the label of $\mathrm{K}$ suggests that it has an analysis similar to that of DPs and PPs. This is clearly not the case, however, as $\mathrm{CP}-\mathrm{V}$ order does not correlate with $\mathrm{OV}$ order so neatly. It is also unclear how the matrix $\mathrm{CP}$ could be built up in this fashion since it is not selected by a higher $\mathrm{V}^{0}$. As evidence for (16) Kayne (p. 226) notes that the internal word order of embedded clauses in Estonian and Finnish varies with respect to adjunct/argument status of the clause. This happens only in non-finite clauses, however. I leave the following, then, to future research. It is possible that finite clauses are introduced as complete CPs, which are selected by $\mathrm{V}^{0}$, while non-finite clauses are built up along the lines of (16). ${ }^{\mathrm{xi}}$ This solves the problem of how the root CP is built in the absence of a super-ordinate $\mathrm{V}^{0}$ and also explains why non-finite clauses are restricted to embedded contexts.

Embedded clauses in Hixkaryana are exclusively nominalized non-finite clauses. Some of these clauses appear to have clause-final complementizer type elements; however, I analyze these as postpositions. Thus the issues raised in the preceding paragraph do not surface.

\subsection{Against Headedness}

Various Greenbergian properties are associated with the distinction between VO and OV word order. However, a number of languages exhibit properties of both VO and OV. For instance, prepositions are associated with VO languages, while postpositions are associated with OV languages. This correlation is not perfect, however. Many Germanic languages are typically OV, but are prepositional. Also, Persian is OV, but prepositional, and its clausal complements are post-verbal. Relative clauses are also correlated with OV/VO order. Post- 
nominal relative clauses are associated with VO languages, while pre-nominal relative clauses are associated with OV languages. However, Chinese languages are uniformly VO, but all typically exhibit pre-nominal relative clauses. English is VO, but exhibits some prenominal non-finite relative clauses (a recently arrived letter). Finally, wh-movement is associated with VO order, while lack of $w h$-movement is associated with OV order. As I have seen above, Hixkaryana has OV order, but exhibits wh-movement (Derbyshire 1979). Also, Chinese exhibits VO order, but $w h$ in situ. Thus, many languages exhibit some or many OV properties, but no language has been shown to be completely OV, even Japanese as suggested by Kayne (2003). (See also Kroch 2001, who argues that most languages display head parameter inconsistencies.)

Many languages appear to have some left-headed projections and some right-headed projections. Ideally, the head parameter setting should be uniform for any given language. Mixed headedness would severely over-generate the number of possible language types. For instance, in German, the $v \mathrm{P}, \mathrm{TP}$, and $\mathrm{VP}$ (sometimes), are right-headed, while all others are left-headed. Likewise, in Kwa languages, the DP is right-headed, the PP can exhibit either order, and the VP can also exhibit either order, varying with aspect (Aboh 2004).

Finally, I point out that assuming a Headedness Parameter has obscured some generalizations that would otherwise remain unnoticed. Kayne (2003) discusses many of these and I concentrate on the generalization in (3) in this chapter. To be sure, the asymmetry in (3) would remain mysterious under a Headedness parameter, but invites an AS analysis. ${ }^{\text {xii }}$

Richards (2008) proposes a modified Headedness Parameter that includes a reimplementation of the LCA whereby parameterized deletions of certain orderings take place at PF. This is based on the notion that a head and its complement form a point of symmetric c-command (in the sense of Moro 2000), a problem that is particularly acute with pronominal objects. ${ }^{\text {xiii }}$ 


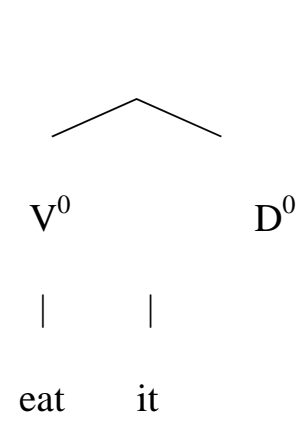

Richards states that the same problem doesn't exist for specifiers, as they asymmetrically ccommand the head and complement. He argues that this is responsible for the universal Spechead order (see also Oishi 2003); while much cross-linguistic variation is found in headcomplement order. It is not quite true, however, that specifiers fail to give rise to LCA violations. A single-headed element (such as a clitic or lexical root, say) could merge in the specifier of an XP and form a point of symmetric c-command with the next higher head up. In the following example, $\mathrm{X}^{0}$ and $\mathrm{Z}^{0}$ form a point of symmetric c-command. ${ }^{\mathrm{xiv}}$

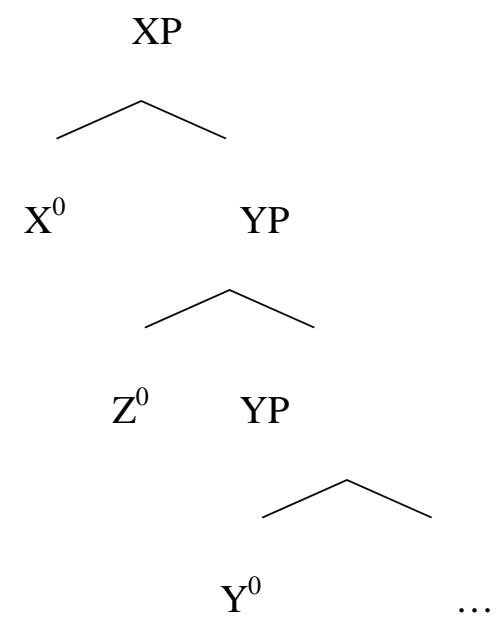

Recall that Richards' observed that the point of symmetric c-command between a head on its complement (when also a head) was problematic for the LCA. This is why he proposed that 
the order between a head and its complement is parameterized (hence stipulated). Applying the same line of reasoning leads us to posit that the order between $\mathrm{X}^{0}$ and $\mathrm{Z}^{0}$ in (18) is also parameterized. $^{\mathrm{xv}}$

Another issue with Richards' proposal (though equally problematic with any Headedness based approach) concerns clausal complements. Since Richards' proposal parameterizes the order between a head and a complement, it is predicted that all complements to $\mathrm{V}^{0}$ are uniformly to the left or right, depending on the parameter setting. Without any further refinement to the proposal, it is predicted that clausal complements appear to the left of the verb in Germanic OV languages, contrary to fact. ${ }^{\mathrm{xvi}}$ I discuss one final concern with Richrards' proposal with respect to complementizers. Richards' proposal works nicely for auxiliaries in that it captures the fact that they frequently appear postverbally, from lowest to highest, (19). What the analysis fails to capture is the fact that the complementizer is consistently clause-initial. These facts about German (and other casual OV languages) could be overcome by various movement operations; however, this is exactly what Richards was trying to avoid by dismissing Antisymmetry in favour of the Headedness Parameter.

$$
\begin{aligned}
& \text {.. daß er den Apfel essen sollen hat hould has.3sg } \\
& \text { that he the apple eat nat to eat the apple.' }
\end{aligned}
$$

A reviewer has also suggested that underlying [vp $\mathrm{O}$ V] order would capture the lack of OSVS order very simply. While this of course is true, what it fails to predict is the generalization given above, namely, that SOV languages rarely disallow SOXV while OVS languages strictly disallow OXVS. If we allow underlying OV order for Hixkaryana, then we 
would expect to find some SOV languages with the properties of Hixkaryana reported here, which we do not.

Modifying Richards' analysis appropriately, one could argue that Hixkaryana has the following parameter setting, or that asymmetric c-command encodes linear subsequence, thereby parameterizing the LCA (as in Compton 2006):

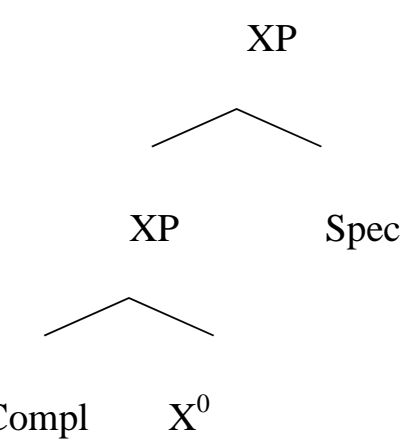

If OVS results from a right specifier, then the fronted wh-phrases and topicalized phrases in Hixkaryana are unexpected as are the fronted focused phrases that Olawsky (2007) reports for Urarina. In fact, if (20) were a possibility, then I would expect to find right-peripheral Abar material in language more frequently; however, such phenomena are glaringly absent. ${ }^{\text {xii }}$ Following the mirror principle (Baker 1985) the structure in (20) predicts a high degree of prefixing on the verbal complex with valency changing morphology appearing closest to the root on the left and aspect, tense and agreement morphology further out. I do not find this, however. Olawsky (2006: 456ff) reports the following general order for morphemes on the verbal complex in Urarina.

\section{V-CAUS-ASP-AGR}

What is observed, then, is that the morpheme order is consistent with S-H-C order. 


\section{Antisymmetry and Word Order}

Kayne (2003) proposes that postpositions arise by virtue of ghost projections (described below), which are labelled by prime notation $\left(\mathrm{X}^{\prime} \mathrm{P}\right) .{ }^{\mathrm{xviii}} \mathrm{I}$ assume that prepositions and postpositions are $\mathrm{P}^{0}$ heads, while Case morphology is realized on $\mathrm{K}^{0}$. Given that the $\mathrm{PP} / \mathrm{KP}$ structure is responsible for Case, I generalize the use of ghost projections to all internal arguments with the following proposal.

\section{Proposal: All internal arguments are assigned Case by a functional projection that either has (Japanese, Hixkaryana) or lacks (English, German) a ghost counterpart.}

Thus, in OV languages such as Japanese and Hixkaryana, I propose an $\mathrm{Agr}_{\mathrm{O}} \mathrm{P} / \mathrm{Agr}_{\mathrm{O}}$ 'P shell to check Accusative Case. ${ }^{\text {xix }}$ This proposal captures the tight connection between $\mathrm{OV}$ and postpositions. For convenience, I distinguish between pervasive OV (as in SOV languages such as Japanese and Korean, as well as the OVS languages under consideration here) and casual OV (as in Germanic). In pervasive OV languages VO doesn't occur, clausal complements are typically preverbal, and there is the obligatory presence of postpostions. In casual OV languages VO occurs in some circumstances, clausal complements are typically postverbal, and there is the obligatory use of prepositions. The derivation of postpostional PPs (Kayne 2003) requires ghost P'P as follows. ${ }^{\mathrm{xx}}$ 
(23)

PP

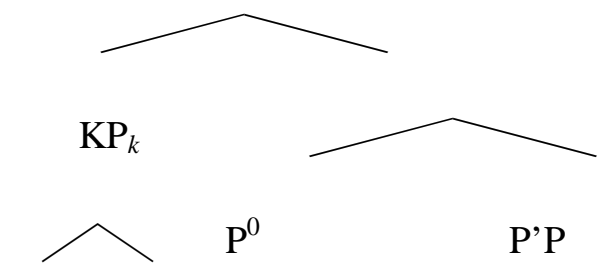

$\mathrm{DP}_{i}$
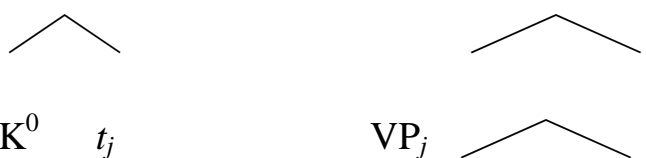

$\mathrm{K}^{0} \quad t_{j}$

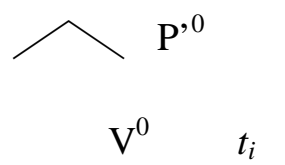

$t_{k}$

Let us posit a dummy $\operatorname{Agr}_{O}$ 'P, a silent copy of $\operatorname{Agr}_{O} P$, along the lines of P'P. Furthermore, I follow Koizumi (1995) and assume a split VP with an $\operatorname{Agr}_{\mathrm{O}} \mathrm{P}$ position for objects, in which the lower $\mathrm{V}^{0}$ is spelled-out. The derivation of pervasive $\mathrm{OV}$, then, is as follows.

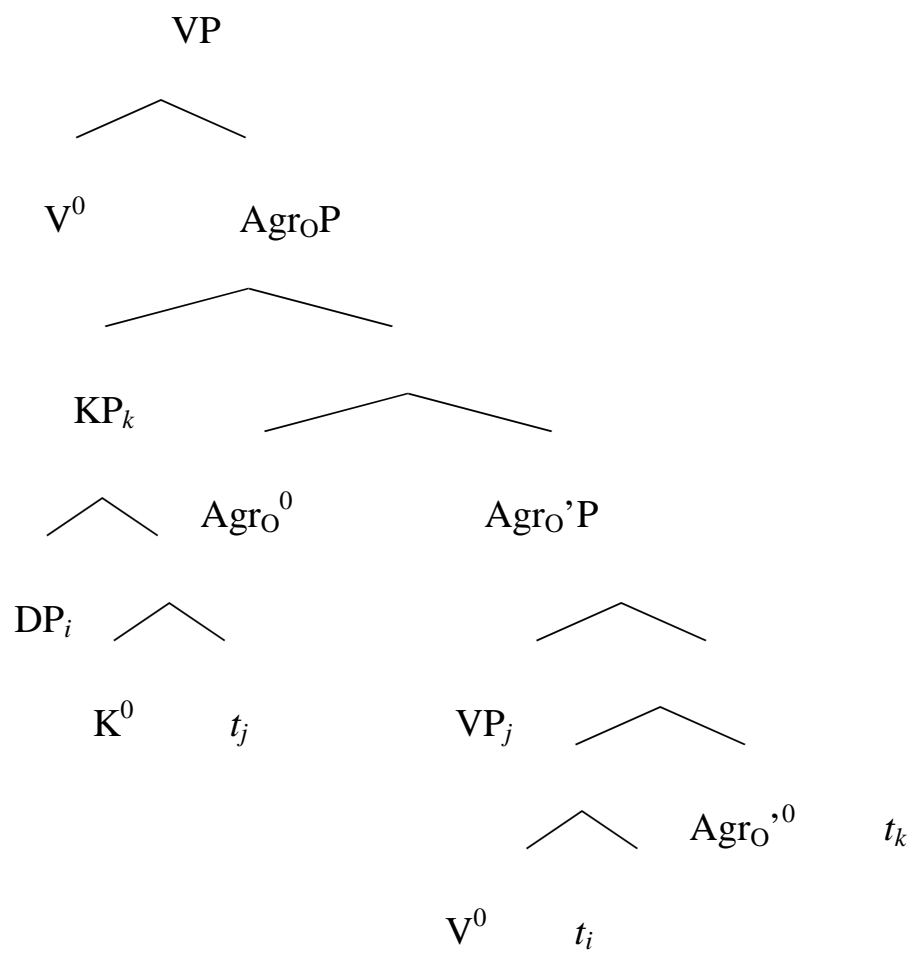


This gives rise to the strict OV adjacency observed in OVS languages. Note that the basic word order for Japanese and Korean tends to have the direct object immediately adjacent to the verb. Given that the object is in its Case checked position, I do not expect it to move any further unless it undergoes scrambling or some (other) A-bar operation. ${ }^{\text {xi }}$ Since EPP in Korean and Japanese assumedly attracts DP rather than VP, the object can raise or scramble higher, deviating from the normal order.

$\begin{array}{cccc}\text { Taroo-ga } & \text { Ginza-de } & \text { susi-o } & \text { tabeta } \\ \text { Taro-NOM } & \text { Ginza-LOC } & \text { sushi-ACC } & \text { eat.PST }\end{array}$

'Taro ate sushi in Ginza.'

Moojang-ka Pusan-ese hoi-lul mek-ess-ta
Moojang-NOM Pusan-LOC sashimi-ACC eat.PST-DECL
'Moojang ate sashimi in Pusan.'

\subsection{Germanic OV lacks Ghost X'P}

The difference in OV/VO order in Germanic is due to object shift or similar phenomena (see Aboh 2004; and the papers in Svenonius 2000). Given the wealth of previous work on this subject, I will confine my remarks to a few relevant observations. Note, for instance, that the direct object is never strictly adjacent to $z u$-infinitives, suggesting that $\mathrm{OV}$ is never a constituent in German. 


...dass er (Äpfel) zu $(*$ Äpfel) kaufen versprochen hat.
...that he apples to (apples) buy promised has
'...that he promised to buy apples.'

Given these differences in OV order between Germanic languages on the one hand, and Japanese, Korean, Hixkaryana and Urarina on the other, an approach that attempts to derive a uniform (i.e., headedness) approach to OV order seems misguided.

We now turn to the derivation of multiple VP-internal elements under the Antisymmetric system that Kayne has set out.

\subsection{Derivation of Multiple PPs/Internal Arguments}

To gain a full understanding of the derivation of OVS order, I must first examine how multiple internal arguments are licensed. Kayne (2003 fn. 41) leaves open the derivation VPs with more than one PP (or a PP and DP internal object). Following Koizumi's approach, there is a VP which can serve as the base for the projection of KP and PP (and P'P in OV languages). Let us consider the derivation of SVOX (where X is a PP, say). ${ }^{\text {xxii, xxiii }}$ 


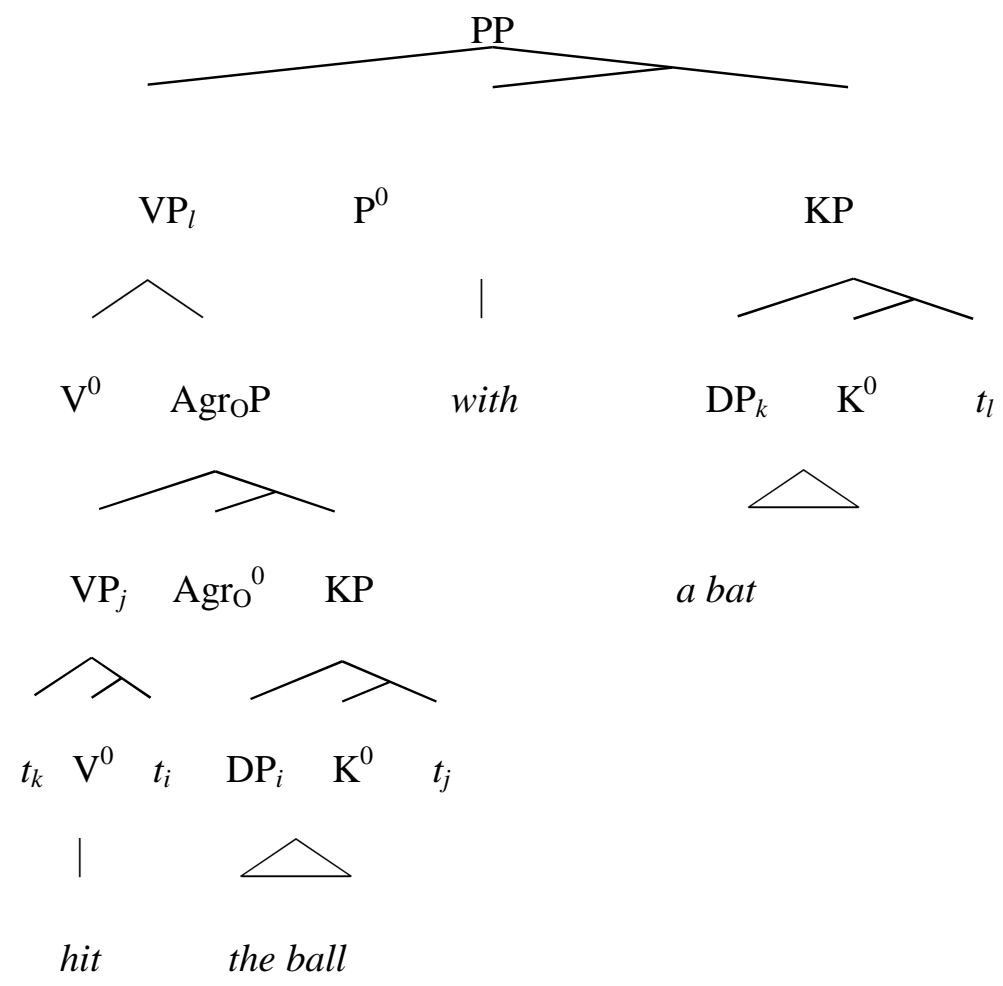

Following Kayne, the DPs are merged in the VP shell devoid of Case or prepositions. $\mathrm{K}^{0}$ then merges with the VP and the direct object raises to SpecKP. $\operatorname{Agr}_{\mathrm{O}}{ }^{0}$ merges with the KP thus formed and the remnant VP raises to $\operatorname{Spec} \operatorname{Agr}_{O} P$. This gives the sequence hit the ball (however with the adjunct $a$ bat still attached. This is the $\operatorname{Agr}_{\mathrm{O}} \mathrm{P}$ shown in (28). The next segment of the VP shell merges with the $\operatorname{Agr}_{\mathrm{O}} \mathrm{P}$ and the process essentially repeats itself. Another $\mathrm{K}^{0}$ merges with this larger VP and the DP 'a bat' raises to SpecKP. Now, the preposition with merges with the KP and the remnant VP raises to SpecPP. This gives the final order shown in (28). Similar derivations are possible for OV languages, as I will show below. I now turn to the derivation of OVS. 


\section{Derivation of OVS}

Recall that the situation in (29) violates most any version of minimality where the two DPs are of the same type (Rizzi 1990) and are not in the same minimal domain (Chomsky 1995).

$$
\mathrm{DP}_{i} \ldots \mathrm{DP}_{j} \ldots t_{i}
$$

Collins (2005) argues such a scenario can arise by smuggling the higher DP inside a larger, non-DP constituent.

$$
[\mathrm{XP} \ldots \mathrm{DP} \ldots]_{i} \ldots \mathrm{DP}_{j} \ldots t_{i}
$$

Consider this scenario in light of Massam's (2000) proposal on verb initial word order in Niuean (see also Cole and Hermon 2008; Coon to appear).

Parameter: EPP satisfied by DP (French, English) or VP (Niuean, Hixkaryana)

Related to this parameter is the following contrast. Kayne (2003) discusses the relative availabilty of OXV (X an adjunct or other VP-internal material) in OV languages, while VXO is absent in many VO languages (such as English). Surprisingly, OXV is absent in OVS languages (Derbyshire 1979; Olawsky 2007, p. 60). This falls out if OV is fronted as a VP-constituent in OVS as a result of EPP-VP rather than the result of object scrambling coupled with some kind of right-adjoined subject. Since OV moves as a unit, there is no opportunity for adjoined material to interpolate between the two.

We illustrate now the derivation of the following Hixkaryana sentence. 
b ryekomo yotahano wos

biryekomo y-otaha-no

boy
(Derbyshire, 1979, p. 38, ex (85a))

wosi

AGR-hit-PST woman

'The woman hit the boy.'

The derivation, then, proceeds as follows. The verb takes a bare DP as a complement.

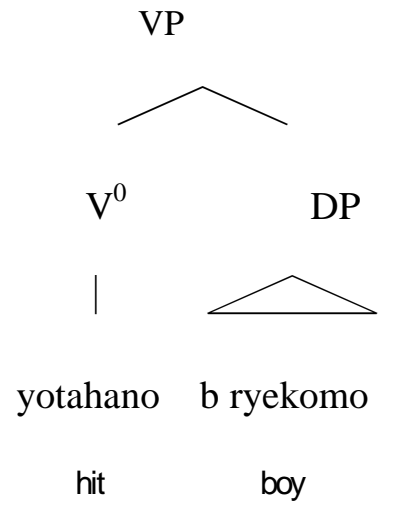

Then, the VP merges with $\mathrm{K}^{0}$ and the DP raises to SpecKP.

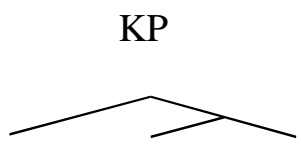

$\mathrm{DP}_{i}$

VP
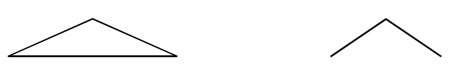

b ryekomo

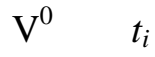

boy

$$
\text { yotahano }
$$

hit 
A ghost $\operatorname{Agr}_{\mathrm{O}}{ }^{0}{ }^{0}$ subsequently merges with DP, and the remnant VP raises to Spec $\operatorname{Agr}_{\mathrm{O}}{ }^{\prime} \mathrm{P}$.

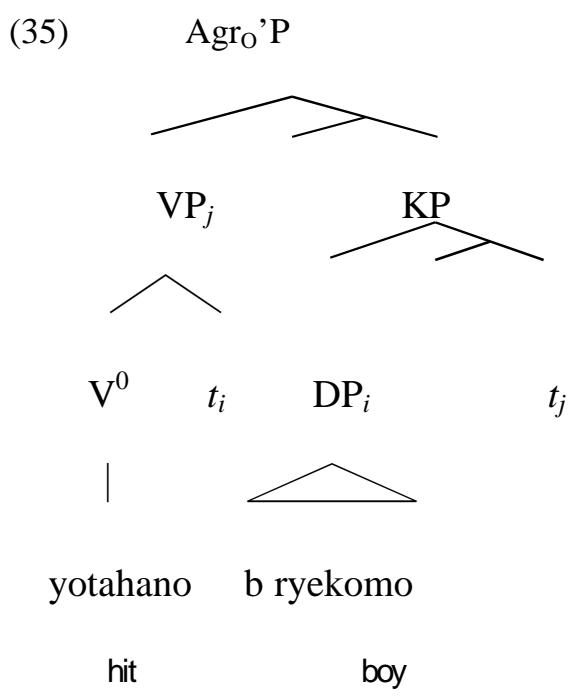

This is followed by Merge of the true $\operatorname{Agr}_{\mathrm{O}}{ }^{0}$ with $\mathrm{Agr}_{\mathrm{O}}$ 'P and raising the remnant KP to Spec $\operatorname{Agr}_{O} P$. Finally the VP shell is closed off by merging in the higher, empty $V^{0}$. ${ }^{x i v}$ 
(36)

$$
\text { VP }
$$

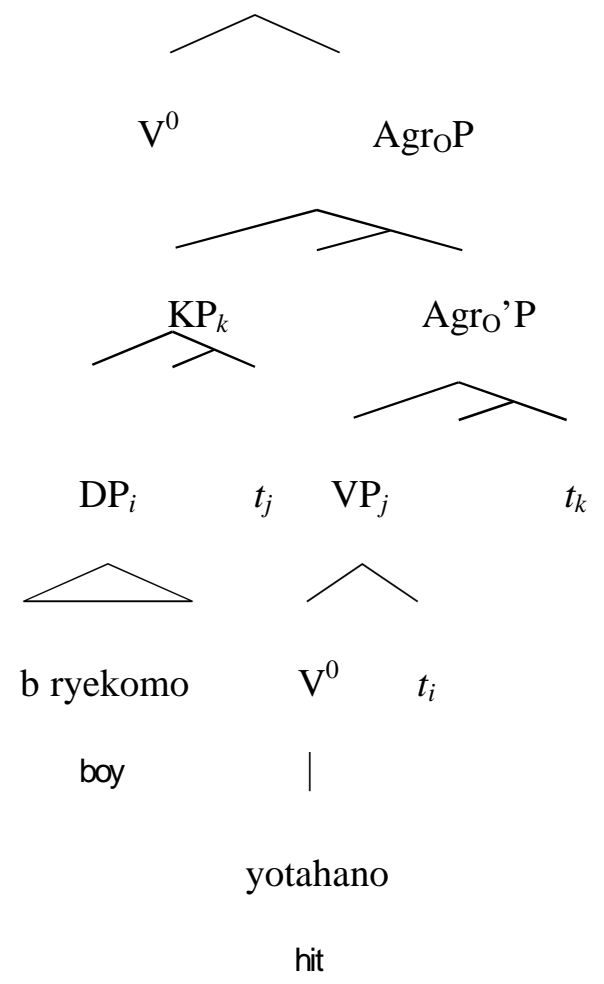

We have derived OV order for the Hixkaryana sentence above within a VP shell that will subsequently be raised. Next, I introduce the external argument and derive the rest of the clause. First, $v^{0}$ merges with the VP, and the subject merges in SpecvP. I address the issue of $\operatorname{Agr}_{S} \mathrm{P}$ later. $^{\mathrm{xxv}}$

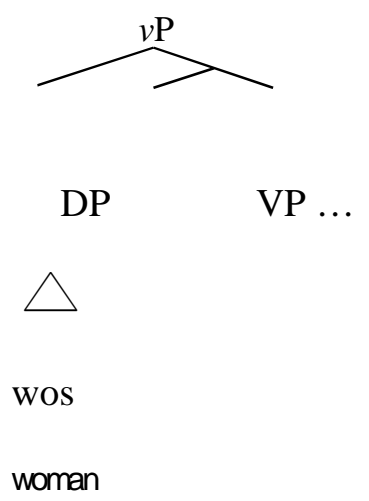


Then, TP merges in and attracts VP (rather than DP) to SpecTP to satisfy EPP.

$\mathrm{TP}$

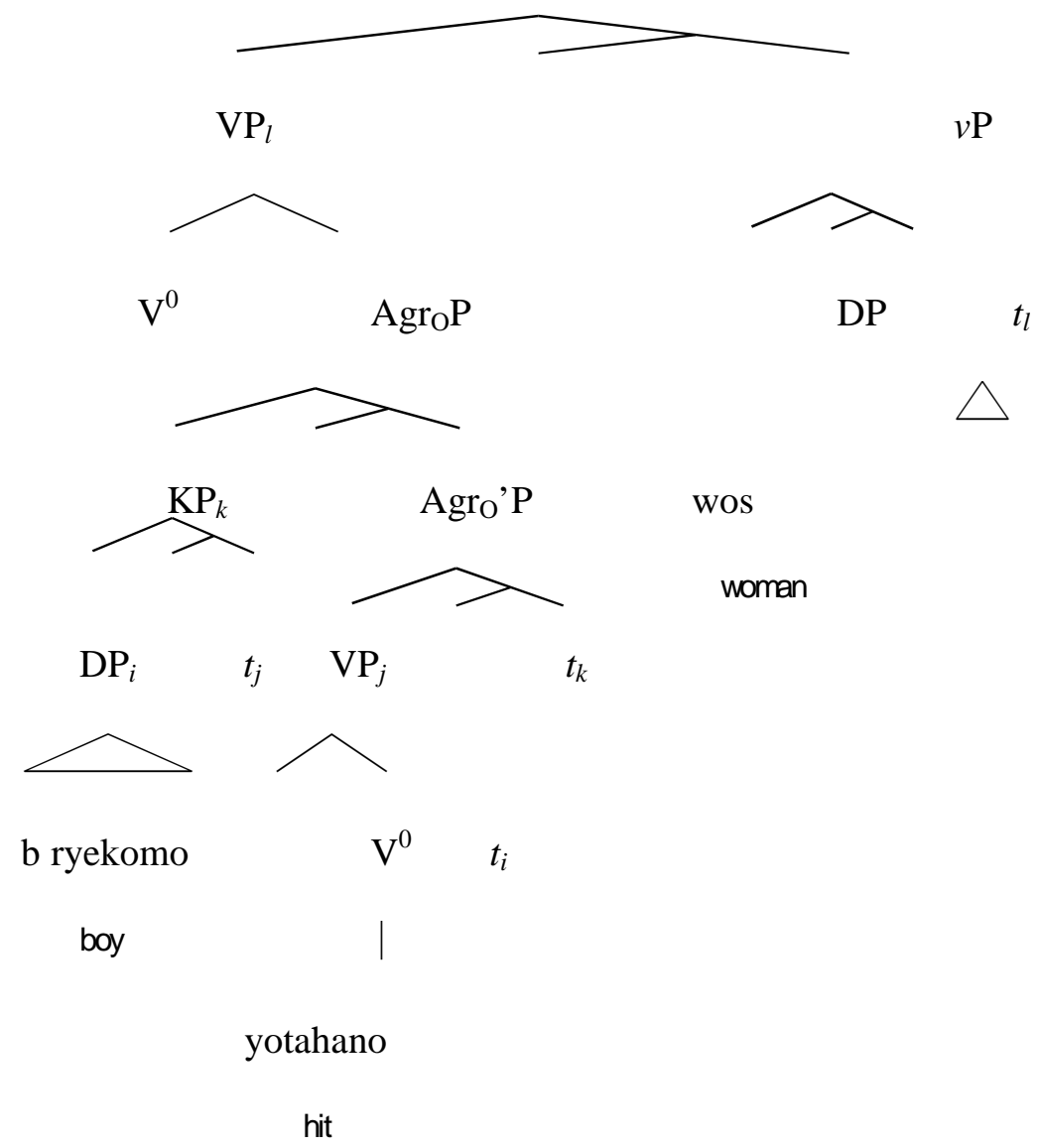

We have thus derived the basic OVS word order for Hixkaryana. ${ }^{\text {xxi }}$ Before continuing, I say a brief word about the VP fronting analysis for Niuean that Massam proposes, in which VSO order arises by object movement out of the VP to a Case checking position and subsequent movement of the VP. (VOS order is derived by VP movement with an in situ object.) The current analysis essentially makes use of the same general mechanism to derive OVS order for Hixkaryana. So, why the difference in word order between Hixkaryana and Niuean? Massam argues that full DP objects in Niuean undergo a kind of object shift to a $v \mathrm{P}$ external projection (namely, to the specifier of Abs(olutive)P), which is 
related to the ergative properties of that language (Coon in press makes a similar proposal for Chol, also an ergative-absolutive language). This movement is not found in Hixkaryana, an essentially nominative-accusative language, rather, the object in Hixkaryana raises only as far as the left edge of the VP and carried along when the VP/vP raises to SpecTP. Furthermore, VOS order in Niuean (and in Chol) is available only when the object nominal is impoverished - that is, when it lacks $\mathrm{D}^{0}$ elements and case marking, although number marking and adjectives may be present. Massam and Coon argue that the morphologically impoverished object remains in situ (giving rise to Pseudo Noun Incorporation in Massam's terms). Thus, VP fronting in Niuean and in Chol involve raising of a V-NP sequence rather than a DP-V sequence as in Hixkaryana.

The chart below summarizes how the various word orders under discussion arise. ${ }^{\mathrm{xxvii}}$ In the next section I discuss further aspects of OVS languages with PPs. Specifically, I address how PPs are typically clause-final in Hixkaryana and clause-initial in Urarina.

\begin{tabular}{|c|c|c|}
\hline & ghost projections present & no ghost projection \\
\hline EPP - DP & Japanese-type SOV & $\begin{array}{c}\text { SVO (no object shift) } \\
\text { German-type SOV (with } \\
\text { object shift) }\end{array}$ \\
\hline $\mathrm{EPP}-\mathrm{VP}$ & OVS & $\begin{array}{l}\text { VOS (no object shift) } \\
\text { VSO (with object shift) }\end{array}$ \\
\hline
\end{tabular}

\subsection{XOVS, OVSX, and *OXVS}

OXVS is ruled out by VP fronting of a constituent containing only OV, which is required to smuggle the $\mathrm{O}$ across the $\mathrm{S}$. In SOV languages such as Japanese, the $\mathrm{O}$ can easily undergo scrambling across an adverb (but remain below the subject), giving rise to SOXV. I must 
show how the OV sequence is able to move as a unit independently of the PP. Recall the derivations for a VP containing both an object DP and PP from above and consider the derivation for the following sentence. I abstract away from the position of the adverb for simplicity.

(39) b ryekomo komo yonyetxkon kamara txetxa wawoamnyehra

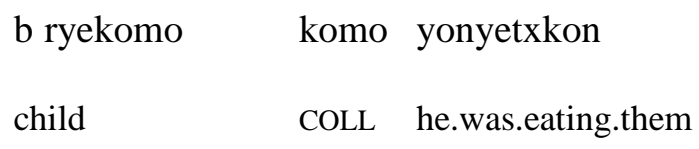

kamara txetxa wawo amnyehra
jaguar forest in $\quad$ long.ago

'The jaguar used to eat children in the forest long ago.'

First, the VP is constructed as above, giving rise to OV order. Once the VP is fully formed, the $\mathrm{P}^{0}$ and ghost $\mathrm{P}^{, 0}$ are merged in to form the post-PP. This gives rise to the derivation in (40). 
(40)

PP

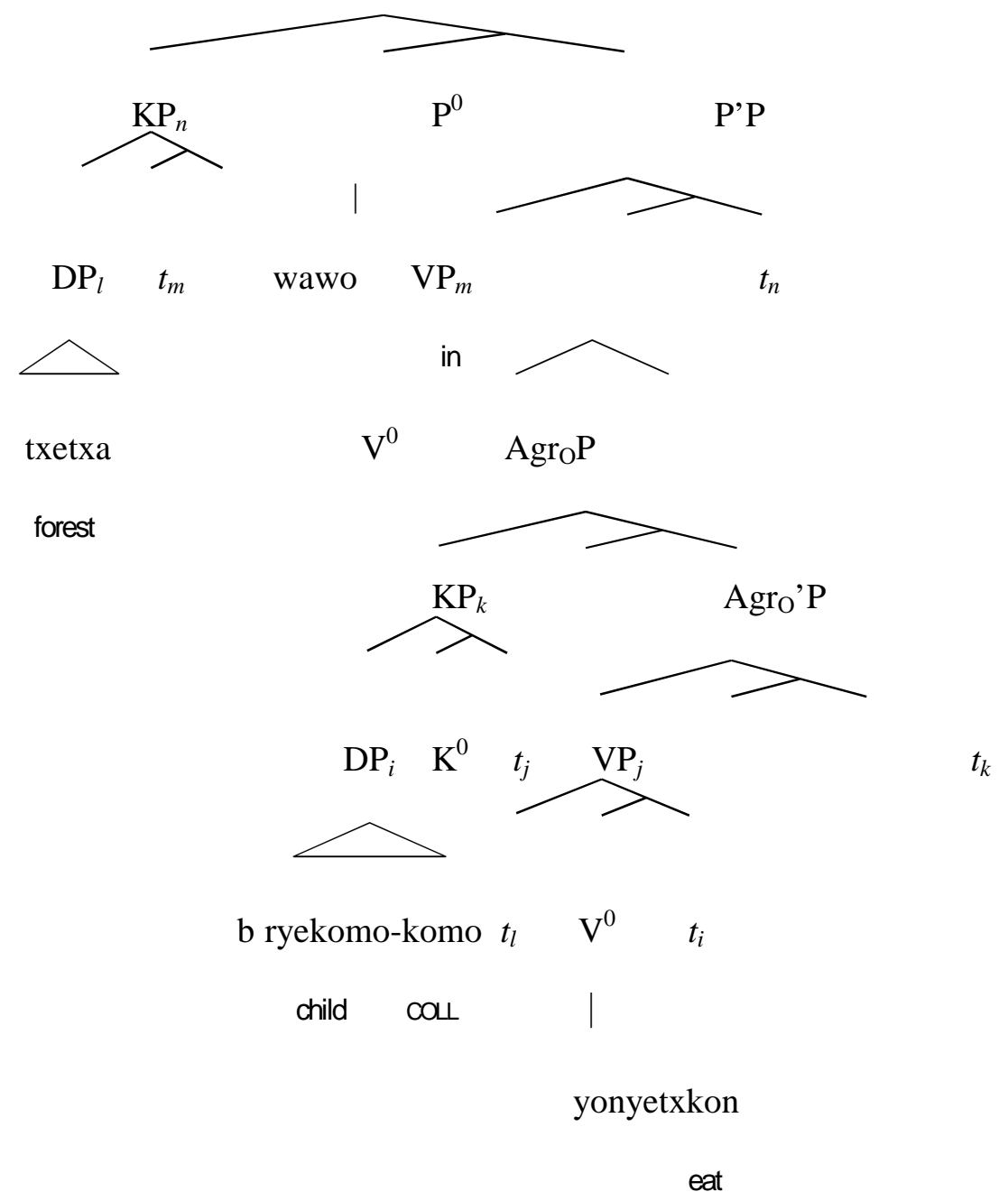

The VP (labelled $\mathrm{VP}_{m}$ ) will subsequently be fronted, smuggling the object above the subject.

Next, the subject is introduced in $v \mathrm{P}$. Note that $v^{0}$ is not introduced until after the Case checking mechanisms for the internal arguments have been discharged. This results in a seemingly unconventional structure in (41), where $v^{0}$ takes PP as a complement. I argue that this is no different from other approaches that assume a variety of functional projections between $v^{0}$ and $\mathrm{V}^{0}$ such as an inner AspP (Travis 1991) or ApplP (Pylkkänen 2008). 
(41)

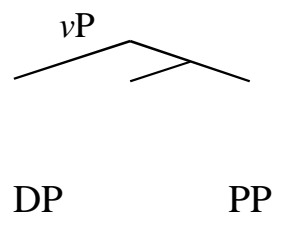

Finally, VP raises to SpecTP, smuggling $\mathrm{O}$ across $\mathrm{S}$ and abandoning the PP in its clause final position.

(42)

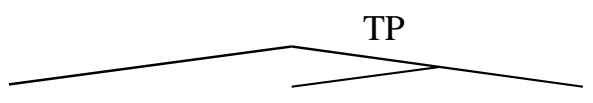

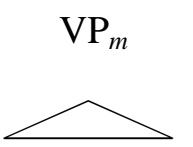

obj. V

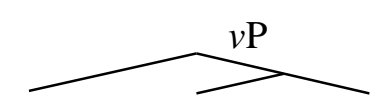

DP
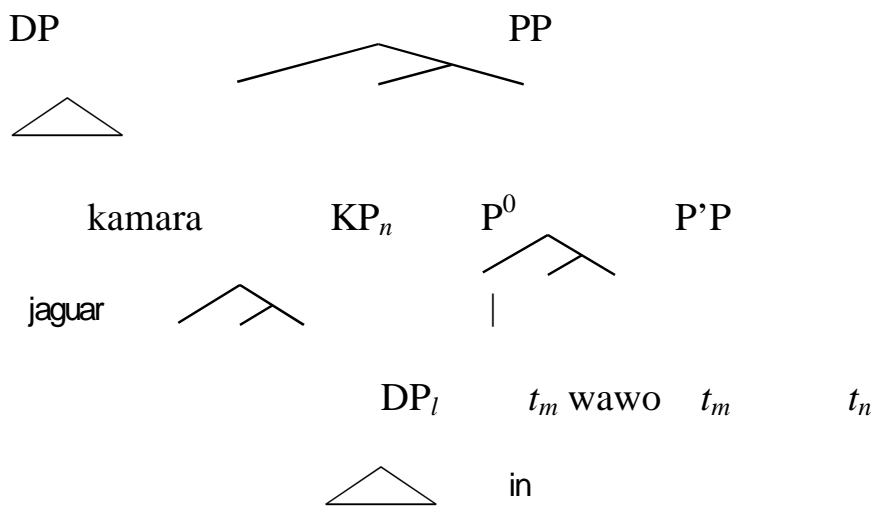

txetxa

forest

We turn now to the derivation of clause-initial PP in Urarina. Initial PPs are more common in Urarina than in Hixkaryana. Olwasky (2007) shows that PPs in Urarina can pattern both as XOVS and OVSX (with a moderate preference for clause-initial PPs). 
Derbyshire (1979) shows clearly that OVSX is the unmarked order for Hixkaryana, where XOVS is possible when $\mathrm{X}$ is focussed or emphatic. The underlying OVSX order simply results from the abandonment of the remnant PP. In Urarina, the remnant PP typically raises to position of prominence in the left periphery, while this movement is not required in Hixkaryana. I take this to be some kind of scrambling that is not yet well understood. ${ }^{\text {xxviii }}$

\subsection{Case and the Licensing of External Arguments}

Let us assume that subjects are Case-marked the same way as objects - with an $\operatorname{Agr}_{S} \mathrm{P}$ and a potential ghost equivalent. However, the agreement projections in and of themselves are not enough to define Case. As noted by Holmberg (1986), accusative Case is dependent on the presence of an external argument, which, following Kratzer (1996), is introduced by what is now known as $v^{0}$. Likewise, nominative Case is available only in the presence of finite $\mathrm{T}^{0}$ (Alboiu 2006; Chomsky 1981), which, following Chomsky (2006; 2008), is dependent on the presence of $\mathrm{C}^{0}$. Thus, we have the following partial derivation for the external argument. $v$ takes VP as a complement (or PP if there are VP-internal PPs, as shown above), and the subject DP merges in Spec $v \mathrm{P}$. The process is then the same as above. K merges with $v \mathrm{P}$ and the subject DP raises to SpecKP. The ghost $\mathrm{Agr}_{\mathrm{S}}{ }{ }^{0}$ merges with $\mathrm{KP}$ and the $v \mathrm{P}$ raises to SpecAgr ${ }_{S}$ 'P. Finally, the real $\mathrm{Agr}_{\mathrm{S}}{ }^{0}$ merges with $\mathrm{Agr}_{\mathrm{S}}$ 'P and the subject KP raises to $\operatorname{Spec} \operatorname{Agr}_{S} \mathrm{P}$. 


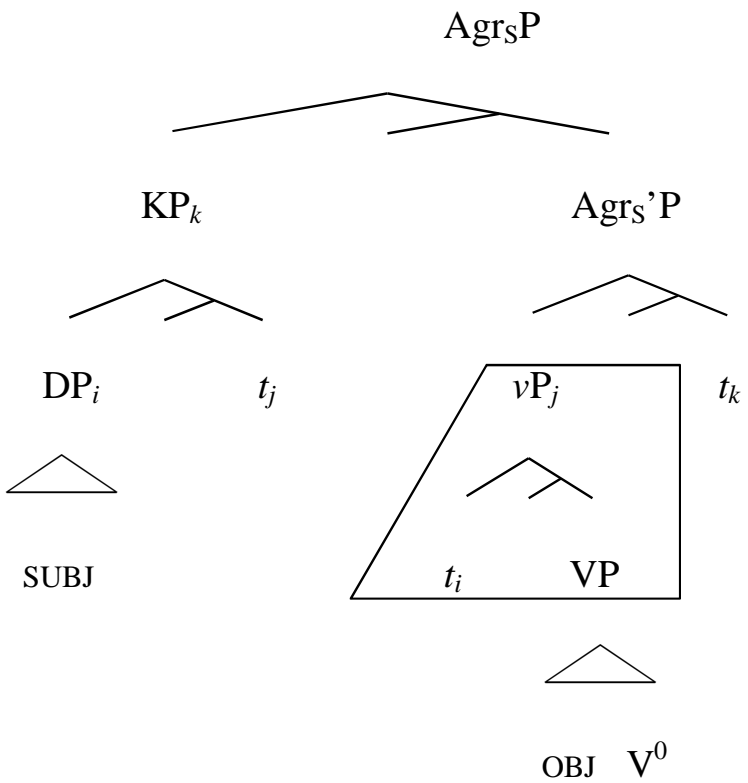

Once $\mathrm{T}^{0}$ is merged with the $\mathrm{Agr}_{S} \mathrm{P}$ in (43), EPP is satisfied by VP (or $v \mathrm{P}$ ) movement (shown in the trapezoid), giving rise to OVS order. Note that both TP and CP are required for finiteness and nominative Case on the subject. This explicit mechanism for Case assignment and word order is necessary for an understanding of word order in embedded clauses, the subject of the next section.

\subsection{Embedded Clauses}

Hixkaryana does not exhibit embedded finite clauses, except for quotes under verbs of saying. Embedded clauses (although rare) are nominalized and display ergative syntax. The unmarked word order is SOV, with the possibility of clause-final postpositions.

Following Alexiadou (2001), nominalized ergative constructions project extended verbal functional heads up to AspP. ${ }^{\mathrm{xxix}}$ Specifically, TP is absent, and so there is no EPP that triggers subject movement to SpecTP. The consequence for OVS languages, however, is that the OV complex does not raise above subject, but rather remains in situ, thus giving rise to SOV order. Let us make the following proposal (revised from (22) above): 
(44) Case-marked arguments have uniform licensing mechanisms within one and the same language: They either have ghost X'Ps (Hixkaryana, Japanese) or lack them (English, German).

We further assume that the clause-final "complementizer" elements are really functional adpositions (thus, a more accurate translation of toko would be 'during' rather than 'when'). Non-finite clauses, then, are licensed the same way PPs are. Thus, the nominalized subordinate clauses are formed as follows - derivation of (9) shown with English words in place. $^{\mathrm{xxx}}$

$$
\text { [DP by.me jaguar AGR-seeing.of-when] }
$$

$$
\text { V selects DP }
$$

$$
\begin{aligned}
& \text { see [DP jaguar] } \\
& \text { K selects VP } \\
& \mathrm{K}[\mathrm{vP} \text { V DP] } \\
& \mathrm{DP} \rightarrow \mathrm{SpecKP} \\
& {\left[\mathrm{KP} \mathrm{DP}_{i} \mathrm{~K}^{0}\left[\mathrm{VP} \mathrm{V}^{0} t_{i}\right]\right]} \\
& \text { ghost Agro' selects KP } \\
& \operatorname{Agr}_{\mathrm{O}}{ }^{\prime}\left[\mathrm{KP} \mathrm{DP}_{i} \mathrm{~K}^{0}\left[\mathrm{vP} \mathrm{V}^{0} t_{i}\right]\right] \\
& \mathrm{VP} \rightarrow \text { SpecAgro'P }^{\prime} \\
& {\left[\text { Agro'P }\left[\mathrm{VP} \mathrm{V}^{0} t_{i}\right]_{j} \mathrm{P}^{, 0}\left[{ }_{\mathrm{KP}} \mathrm{DP}_{i} \mathrm{~K}^{0} t_{j}\right]\right.} \\
& \operatorname{Agr}_{O}{ }^{0} \text { selects } \operatorname{Agr}_{O}{ }^{\prime} \mathrm{P} \\
& \operatorname{Agr}_{\mathrm{O}}{ }^{0}\left[\text { Agro'P }\left[\mathrm{vP} \mathrm{V}^{0} t_{i}\right]_{j} \operatorname{Agr}_{\mathrm{O}}{ }^{0}\left[\mathrm{KP} \mathrm{DP}_{i} \mathrm{~K}^{0} t_{j}\right]\right. \\
& \mathrm{KP} \rightarrow \mathrm{Spec}^{\mathrm{Agr}} \mathrm{P} \\
& {\left[\text { AgroP }\left[\mathrm{KP}_{\mathrm{DP}} \mathrm{K}^{0} t_{j}\right]_{k} \operatorname{Agr}_{\mathrm{O}}{ }^{0}\left[{ }_{\text {Agro }} \mathrm{P}\left[\mathrm{vP}^{0} \mathrm{~V}_{i}\right]_{j} \operatorname{Agr}_{\mathrm{O}}{ }^{0} t_{k}\right]\right.}
\end{aligned}
$$

The structure in (45) is embedded under a VP shell as described above giving rise to the order [vp jaguar see]. At this stage, the external argument is merged in and the structure projects up to AspP (following Alexiadou). The details of the VP derived above are left out in the following derivation for space. The final tree is given below. 
$v^{0}$ [vp jaguar see]

[vP [DP me $v^{0}[\mathrm{vP}$ jaguar see] $]$

$\operatorname{Asp}^{0}\left[{ }_{v \mathrm{P}}[\mathrm{DP} \mathrm{me}] v^{0}[\mathrm{vP}\right.$ jaguar see $\left.]\right]$

$\left[\operatorname{AspP} \operatorname{Asp}^{0}[\mathrm{vP} \text { jaguar see }]_{i}\left[{ }_{v \mathrm{P}}[\mathrm{DP} \mathrm{me}] v^{0} t_{i}\right]\right]$

$\mathrm{K}^{0}\left[\right.$ AspP $\left.[v P \text { jaguar see }]_{i}\left[{ }_{v \mathrm{P}}[\mathrm{DP} \mathrm{me}] v^{0} t_{i}\right]\right]$

$\left[\mathrm{KP}[\mathrm{DP} \mathrm{me}]_{j} \mathrm{~K}^{0}\left[\mathrm{AspP}[\mathrm{vP} \text { jaguar see }]_{i}\left[{ }_{\nu \mathrm{P}} t_{j} v^{0} t_{i}\right]\right]\right]$

$\left.\mathrm{P}^{, 0}\left[\mathrm{KP}[\mathrm{DP} \mathrm{me}]_{j} \mathrm{~K}^{0}[\text { AspP [vP jaguar see }]_{i}\left[{ }_{v \mathrm{P}} t_{j} v^{0} t_{i}\right]\right]\right]$ $v^{0}$ selects VP

subject merges in

Asp $^{0}$ selects $v \mathrm{P}$

$\mathrm{VP} \rightarrow$ SpecAspP

$\mathrm{K}^{0}$ selects AspP

Subject DP $\rightarrow$ SpecKP

ghost $\mathrm{P}^{0}$ selects KP

AspP $\rightarrow$ SpecP'P [P'P $\left.\left.\left[\text { AspP }[\text { vP jaguar see }]_{i}\left[{ }_{v \mathrm{P}} t_{j} v^{0} t_{i}\right]\right]_{k} \mathrm{P}^{, 0}{ }_{\text {KP }}[\mathrm{DP} \text { me }]_{j} \mathrm{~K}^{0} t_{k}\right]\right] \mathrm{P}^{0}$ ('by') selects P'P by [P'P $\left.\left[\text { AspP }[\mathrm{vP} \text { jaguar see }]_{i}\left[{ }_{\nu \mathrm{P}} t_{j} v^{0} t_{i}\right]\right]_{k} \mathrm{P}^{, 0}\left[\mathrm{KP}[\mathrm{DP} \mathrm{me}]_{j} \mathrm{~K}^{0} t_{k}\right]\right] \mathrm{KP} \rightarrow$ SpecPP $\left[\mathrm{PP}\left[\mathrm{KP}[\mathrm{DP} \mathbf{m e}]_{j} \mathrm{~K}^{0} t_{k}\right]_{l} \mathbf{b y}\left[\mathrm{P}^{\prime} \mathrm{P}\left[\mathrm{AspP}[\mathrm{vP} \mathbf{j a g u a r} \mathbf{s e e}]_{i}\left[{ }_{v \mathrm{P}} t_{j} v^{0} t_{i}\right]\right]_{k} \mathrm{P}^{, 0} t_{l}\right]\right.$ 


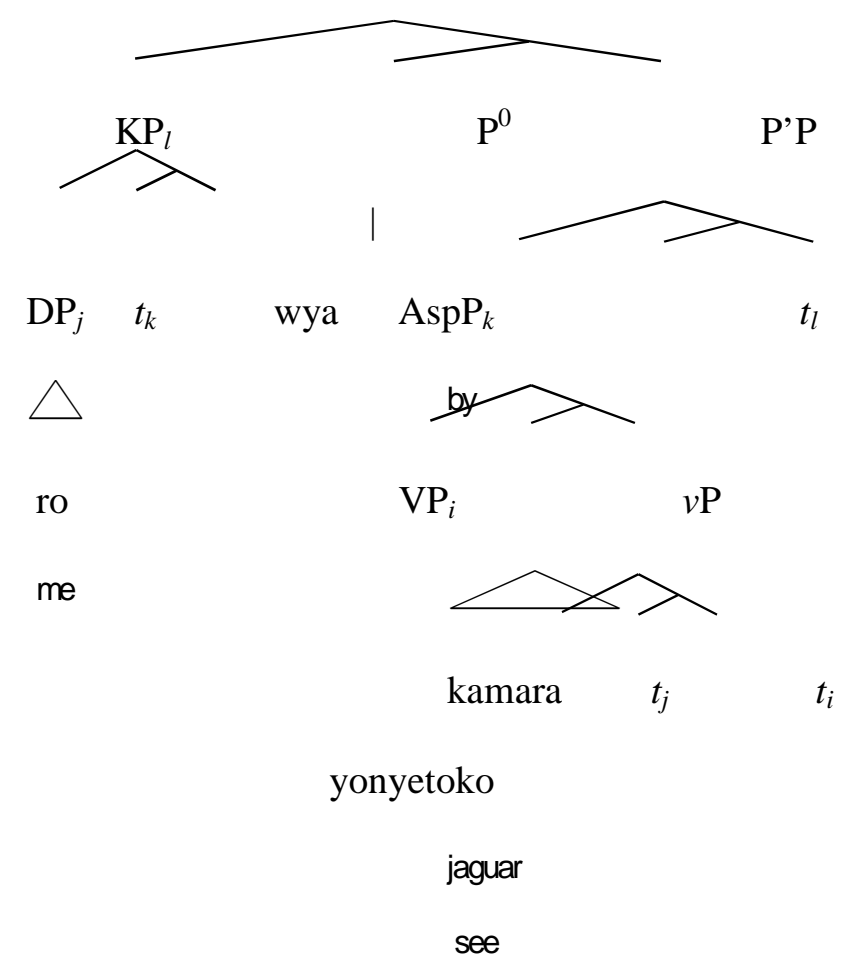

This non-finite clause undergoes nominalization before being selected by the matrix verb. Following the discussion above, the postposition (the equivalent of when, or during according to the suggestion above) is merged high, above the superordinate verb.

Recall that embedded clauses in Urarina are finite and exhibit OVS order. This is consistent with the overall approach argued for here, since the same mechanism for OVS order in matrix clauses described in the previous section can account for OVS order in the embedded clause. The analysis presented here, then, ties the difference in word order in embedded clauses in Hixkaryana and Urarina to the difference in finiteness in embedded clauses.

Finally, I discuss object complement clauses in Urarina. Olawsky (2006: 758) reports that object complement clauses regularly occupy the object position (immediately to the left of the verb with no intervening material). Recall also that such clauses are typically non-finite 
or nominalized (obligatorily so when the main and embedded clauses have the same subject). Again, I carry over the derivation for non-finite clauses for Hixkaryana above to Urarina to account for OVS order, when $\mathrm{O}$ is a non-finite clause. More interesting is the case where the object complement is a finite clause. I speculated in section 3 above that finite clauses are introduced differently than non-finite clauses. Specifically, I suggested that they are introduced as complete CPs without the interleaving structures found for nominal and nonfinite complements. The contrast in (14) above seems to support this conclusion; however, the lack of relevant data urges us to proceed with caution and leave a fuller discussion of the syntax of finite clauses within the current framework to future research.

\section{Conclusions}

We have outlined an analysis of OVS languages within an Antisymmetric framework that hinges on two important microparameters. First, I have adopted Massam's proposal that EPP can be satisfied by VP rather than by DP in some languages. I have also proposed that the presence or absence of ghost $\mathrm{P}^{\prime} \mathrm{Ps}$ (and ghost $\mathrm{Agr}_{\mathrm{O}}{ }^{\prime} \mathrm{Ps}$ ) is also subject to parametric variation, giving rise to the OV/VO distinction (and the correlated postposition/preposition distinction). The problem of raising an object DP over an intervening subject DP was solved by the notion of smuggling introduced by Collins. The object DP is smuggled across the subject DP by VP movement to satisfy the EPP. I have also seen that an Antisymmetric approach to syntax captures the *OXVS constraint in a straightforward way, while such a constraint would remain mysterious under a symmetric view of syntax. Thus, OVS languages, rather than being problematic for the theory of Antisymmetry, turn out, under closer inspection, to offer support for it. 


\section{References}

Aboh, Enoch (2004), The Morphosyntax of Complement-Head Sequences: Clause Structure and Word Order Patterns in Kwa (Oxford: Oxford University Press).

Alboiu, Gabriela (2006), 'Feature-Inheritance and Case values in Nominative Accusative Systems', (York University).

Alexiadou, Artemis (2001), Functional Structure in Nominals: Nominalizations and Ergativity (Amsterdam: John Benjamins).

Baker, Mark C. (1985), 'The Mirror Principle and Morphosyntactic Explanation', Linguistic Inquiry, 16 (3), 373-416.

Barrie, Michael (2006a), 'Dynamic Antisymmetry and the Syntax of Noun Incorporation', Ph.D. Dissertation (University of Toronto).

--- (2006b), 'On unifying antisymmetry and bare phrase structure', in Bateman Leah and Ussery Cherlon (eds.), 35th meeting of the North East Linguistic Society (Amherst, MA: GLSA Publications), 103-14.

--- (2009), 'Clausal Temporal Adjuncts: Against Late Adjunction', paper given at 83nd Annual Meeting of the Linguistic Society of America, San Francisco, California, January $8-11,2009$.

Bianchi, Valentina (1999), Consequences of Antisymmetry: Headed relative clauses (Berlin: Mouton de Gruyter).

Boeckx, Cedric and Stjepanović, Sandra (2001), 'Head-ing toward PF', Linguistic Inquiry, 32 (2), 345-55.

Chomsky, Noam (1981), Lectures on Government and Binding (Dordrecht: Foris).

--- (1995), The Minimalist Program (Cambridge, MA: MIT Press).

--- (2006), 'Approaching UG from Below', (MIT). 
--- (2008), 'On Phases', in P. Oltero (ed.), Foundational Issues in Linguistic Theory

(Cambridge, MA: MIT Press), 133 - 66.

Cinque, Guglielmo (2005), 'Deriving Greenberg's Universal 20 and Its Exceptions', Linguistic Inquiry, 36 (3), 315-32.

Cole, Peter and Hermon, Gabriella (2008), 'VP Raising in a VOS Language', Syntax, 11 (2), 144-97.

Collins, Chris (2005), 'A Smuggling Approach to the Passive in English', Syntax, 8 (2), 81120.

Compton, Richard (2006), 'Phasal Words and Inverse Morpheme Order in Inuktitut', Generals Paper (University of Toronto).

Coon, Jessica (in press), 'VOS as Predicate Fronting in Chol', Lingua.

--- (to appear), 'VOS as Predicate Fronting in Chol', Lingua.

Déchaine, Rose Marie and Wiltschko, Martina (2002), 'Decomposing Pronouns', Linguistic Inquiry, 33 (3), 409-42.

Derbyshire, Desmond C. (1977), 'Word Order Universals and the Existence of OVS languages', Linguistic Inquiry, 8 (3), 590-99.

--- (1979), Hixkaryana (Lingua Descriptive Studies; Amsterdam: North Holland Publishing Company).

--- (1985), Hixkaryana and Linguistic Typology (Dallas, TX: The Summer Institute of Linguistics and The University of Texas at Arlington).

Guimarães, Maximiliano (2000), 'In Defense of Vacuous Projections in Bare Phrase Structure', University of Maryland Working Papers in Linguistics 9, 90-115.

Holmberg, Anders (1986), 'Word order and syntactic features in the Scandinavian languages and English', Ph.D. Dissertation (University of Stockholm). 
Johnson, Kyle (1991), 'Object Positions', Natural Language \& Linguistic Theory, 9 (4), 577636.

Kayne, Richard (1994), The Antisymmetry of Syntax (Cambridge, MA: MIT Press).

--- (2003), 'Antisymmetry and Japanese', English Linguistics, 20, 1-40.

--- (2009), 'Why is Syntax Antisymmetric', paper given at Theoretical Approaches to Disharmonic Word Orders, Newcastle University.

Koizumi, Masatoshi (1995), 'Phrase Structure in Minimalist Syntax', Ph.D. Dissertation (MIT).

Kratzer, Angelika (1996), 'Severing the External Argument from its Verb', in Johan Rooryck and Laurie Zaring (eds.), Phrase Structure and the Lexicon (Dordrecht: Kluwer), 10938.

Kroch, Anthony (2001), 'Syntactic Change', in Mark Baltin and Chris Collins (eds.), The Handbook of Contemporary Syntactic Theory (Malden, MA: Blackwell), 699-729.

Lasnik, Howard (2001), 'Subjects, Objects and the EPP', in William D. Davies and Stanley Dubinsky (eds.), Ojbects and Other Subjects (Dordrecht: Kluwer), 103-21.

Lee, Felicia Ann (2000), 'Antisymmetry and the Syntax of San Lucas Quiavini Zapotec', Ph.D. Dissertation.

Lounsbury, Floyd Glenn (1949), 'Iroquoian Morphology', Ph.D. Dissertation (Yale University).

--- (1953), Oneida Verb Morphology (New Haven, CT: Yale University).

Massam, Diane (2000), 'VSO and VOS: Aspects of Niuean Word Order', in Andrew Carnie and Eithne Guilfoyle (eds.), The Syntax of Verb Initial Languages (Oxford: Oxford University Press), 97-116.

--- (2001), 'Pseudo Noun Incorporation in Niuean', Natural Language and Linguistic Theory, $19(1), 153-97$. 
May, Robert (1985), Logical Form: Its Structure and Derivation (Cambridge, MA: MIT Press).

Moro, Andrea (2000), Dynamic Antisymmetry (Cambridge, MA: MIT Press).

Neidle, Carol, et al. (2000), The Syntax of American Sign Language: Functional Categories and Hierarchical Structure (Cambridge, MA: MIT Press).

Oishi, Masayuki (2003), 'When Linearity Meets Bare Phrase Structure', Current Issues in English Linguistics, 2, 18-41.

Olawsky, Knut J. (2006), A Grammar of Urarina (Berlin: Mouton de Gruyter).

--- (2007), 'ObViouS OVS in Urarina syntax', in Peter K. Austin and Andrew Simpson (eds.), Endangered Languages (Linguistische Berichte Sonderheft 14), 45-72.

Petronio, Karen and Lillo-Martin, Diane (1997), 'WH-movement and the position of specCP:Evidence from American Sign Language', Language, 73 (1), 18-57.

Pollock, Jean-Yves (1989), 'Verb Movement, Universal Grammar, and the Structure of IP', Linguistic Inquiry, 20 (3), 356-424.

Pylkkänen, Liina (2008), Introducing Arguments (Cambridge, MA: MIT Press).

Rezac, Milan (2006), 'The Interaction of Th/Ex and Locative Inversion', Linguistic Inquiry, 37 (4), 685-97.

Rhodes, Richard A. (1998), 'Clause Structure, Core Arguments, and the Algonquian Relative Root Construction', (University of California-Berkeley).

Richards, Marc D. (2008), 'Desymmetrization: Parametric Variation at the PF Interface', Canadian Journal of Linguistics, 53 (2/3), 275-300.

Richards, Norvin (2001), 'A Distinctness Condition on Linearization', in Karine Megerdoomian (ed.), 20th West Coast Conference on Formal Linguistics (Proceedings of the West Coast Conference on Formal Linguistics. (PWCCFL). Somerville, MA; 20; Somerville, MA: Cascadilla Press), 470-83. 
Rizzi, Luigi (1990), Relativized Minimality (Cambridge, MA: MIT Press).

Rosenbaum, Peter S. (1967), The Grammar of English Predicate Complement Constructions

(Cambridge, MA: MIT Press).

Stowell, Tim (1981), 'Origins of Phrase Structure', Ph.D. Dissertation (MIT).

Svenonius, Peter (ed.), (2000), The Derivation of VO and OV (Amsterdam: John Benjamins)

372.

Torrego, Esther (1998), The Dependencies of Objects (Cambridge, MA: MIT Press).

Travis, Lisa de Mena (1984), 'Parameters and Effects of Word Order Variation', Ph.D.

Dissertation (Massachussets Institute of Techonology).

--- (1991), 'Inner aspect and the structure of VP', paper given at 22nd Meeting of the

Northeast Linguistics Society, University of Delaware.

Uriagereka, Juan (1999), 'Multiple Spell Out', in Samuel Epstein and Norbert Hornstein (eds.),

Working Minimalism (Cambridge, MA: MIT Press), 251-82.

\footnotetext{
* I wish to thank the participants at TADWO and other conferences where this work was presented, as well as the reviewers, for asking difficult and probing questions, thereby improving the presentation. All remaining shortcomings are my own. I greatfully acknowledge the support of the Sogang University Research Grant of 2011.

${ }^{\mathrm{i}}$ I use the term smuggling here loosely as Collins originally used the term to describe an element that is carried above a potential intervener inside a larger element (as is the case here), and then subsequently sub-extracted to a higher position (which is not the case here).

ii Example (1)c resembles a fronted quote, as in the English translation. Derbyshire notes, however, that direct quotes must immediately precede the verb of saying. Thus, the quotes pattern with nominal objects in Hixkaryana and not with quotes in English, which can be separated from the verb of saying by the subject. The generalization here is that all verbal complements in Hixkaryana (and in Urarina) must be immediately preverbal.

${ }_{\text {iii }}$ With a few minor exceptions, abbreviations and interlinear glossing is left intact from their original sources; however, agreement markers are typically glossed as AGR to save space. The following abbreviations are used: ACC - accusative; AGR - agreement; CND - conditional/temporal; CNT - continuous aspect; COLL - collective; DEVLD - devalued; E - declension class in Urarina; EMF - emphatic; FOC - focus; HRS - hearsay; IMPST immediate past; IRR - irrealis; LOC - locative; NEG - negative; NOM - nominative; NZLR - nominalizer; PRT/PART - participial; POSS - possessive; PST - past; SG - singular; SUB - subordinate.

iv Note that the embedded clause has SOV order. This is addressed later in the discussion.

${ }^{v}$ Given the paucity of OVS languages and the fact that I have examined only two here, one may question the validity of this generalization. Nevertheless, the fact that OXVS is not found in these languages must still be accounted for.
} 
${ }^{v i}$ The syntax of quotes is beyond the scope of this paper. Suffice it to say that they have substantially different syntactic properties from finite complement clauses (quotative inversion, set off by heavy pauses, islands for extraction, etc.). Finite complement clauses of the English variety seem to be absent in Hixkaryana.

${ }^{v i i}$ Derbyshire himself does not use the term ergative to describe the syntax of nominalized constructions in Hixkaryana. The following quote, however, makes it clear that he had already observed the ergative properties of this language (Derbyshire 1979: 26).

"The basic word order in finite clauses is OVS. In nominal constructions the NP (i.e. possessor) which is the equivalent of $\mathrm{S}$ in intransitives and $\mathrm{O}$ in transitives, always occurs preceding the derived nominal. The equivalent of $\mathrm{S}$ in transitives is most frequently found occurring before the derived nominal and before the possessor NP, although it can also occur after the nominal."

viii Derbyshire (1979: 165) notes that nominalizing morphology is sometimes left off by many speakers, hence its absence in many of the examples above.

${ }^{\text {ix }}$ Olawsky (p. 767) argues that because the above example contains a post-verbal dependent clause, it must be interpreted as an adjunct rather than as an object. (Hence, he glosses /-ne/ as SUB in (14)a and as CND in (14)b.) I assume Olawsky comes to this conclusion in observance of the general OVS order of this language. Below, however, I discuss the possibility that finite complement clauses do not obey the same syntactic constraints as nominal and non-finite complements.

${ }^{\mathrm{x}}$ There have been various attempts at bringing the LCA in line with the Minimalist Program (Barrie 2006b; N. Richards 2001; Uriagereka 1999). I do not review these here as it does not impinge greatly on the current analysis.

${ }^{x i}$ Kayne proposes that the to-infinitive is actually a PP with a bare VP (or $v \mathrm{P}$ ) complement. Since IP is absent, it requires no $\mathrm{N}^{0}$ to appear as a complement to the matrix verb.

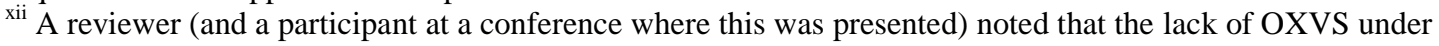
the VP fronting proposal falls out naturally from assuming a right headed structure with no verb movement. In fact, the mechanism I propose admits the possibility of a low VP adjunct (such as a manner adverb), which the headedness approach does not admit. Note, in fact, that in Urarina at least, VP-level adverbs appear at the left edge, suggesting that something larger than a bare VP has raised (assuming a Cinquean adverbial hierarchy). The point here, however, is that the headedness approach does not predict the asymmetry in (3). If OV languages were the result of a right-headed setting, then we would expect just as frequent a ban on OXV in SOV languages as in OVS languages, which we don't. Specifically, the ban on OXVS discussed here is simply a corollary of Kayne's original observation that bans on SOXV are much rarer than bans on SVXO. The reviewer does raise an important empirical point, however. The approach presented here does predict at least some material to intervene between the verb and the object to a very limited degree. This will have to wait for further empirical investigations. This proposal also predicts that OVS should alternate with VSO if object shift out of the VP is available. That is, a remnant VP raises to SpecTP stranding the object. It also predicts that VOS might be found for non-specific or bare objects (as in Massam's pseudo noun incorporation). These prediction will have to wait for future research.

xiii It is likely that pronouns of the English type as shown are actually DPs or $\varphi$ Ps (Déchaine and Wiltschko 2002). Nevertheless, there are assumedly indisputable cases where two heads with lexical material c-command each other. Previously, I argued that this was the motivation for noun incorporation, where a verbal root merges with a nominal root (Barrie 2006a).

${ }^{\text {xiv }}$ To see how this is so, recall that Kayne's definition of c-command refers to segments of a maximal projection. $\mathrm{X}^{0}$ c-commands $\mathrm{Z}^{0}$ because every category that dominates $\mathrm{X}^{0}$ (namely $\mathrm{XP}$ ) also dominates $\mathrm{Z}^{0}$. Note that $\mathrm{YP}$ does not dominate $Z^{0}$ since not all segments of $Y P$ dominates $Z^{0}$. Thus, $Z^{0}$ c-commands $X^{0}$ because every category that dominates $Z^{0}$ (only XP) also dominates $\mathrm{X}^{0}$.

${ }^{\mathrm{xv}}$ (18) is also problematic for a strict Antisymmetric approach, of course. The point here is that Richards' approach does not completely solve the problem of symmetric c-command that BPS introduces. For such approaches see Moro (2000) and Guimarães (2000).

${ }^{x v i}$ A reviewer notes the issue of clausal complements is problematic for Antisymmetry, too. If we assume, as I suggested above, that finite clausal complements are selected as fully formed CPs (while only non-finite clausal complements require the kind of treatment Kayne suggests), then this ceases to be a problem. The clause is selected and remains post-verbal. DPs, on the other hand, must be licensed as described here, ending up preverbal when ghost projections are present. The presence of ghost projections does not affect finite CPs.

xvii The sole exception to this generalization I am aware of is $w h$-movement in ASL, where dislocated $w h$ phrases appear clause-finally. Petronio and Lillo-Martin (1997) argues that $w h$-phrases move to SpecCP on the left with subsequent raising of the remnant clause; however, Neidle et al. (2000) refute this analysis and argue that SpecCP is on the right. 
${ }^{\text {xviii }}$ To avoid confusion, intermediate projections will not appear as X', but rather will appear as XP. Thus, X'P represents only a ghost $X P$ hereafter.

${ }^{x i x}$ Although Chomsky (1995) sought to eliminate agreement projections from UG as they were superfluous, it has been argued that there is some $v \mathrm{P}$-internal projection that hosts objects (Johnson 1991; Rezac 2006). With regards to the subject AgrP, there languages that show tense marking and subject agreement in distinct positions in the verbal complex (such as Northern Iroquoian, Lounsbury 1949), thus requiring a distinct $\operatorname{Agr}_{S} \mathrm{P}$ and TP.

${ }^{\mathrm{xx}}$ Kayne (2003) assumes that the ghost is always null since it appears within the verbal complex and is never part of the nominal phrase. However, many languages require additional verbal morphology when locative expressions are present. Algonquian languages, for example, appear with relative roots - a morpheme inside the verbal complex - when a locative phrase is present in the clause (Rhodes 1998). Iroquoian languages also encode locative phrases with additional verbal morphology (Lounsbury 1949, 1953). Whether these morphemes are amenable to such an analysis is left to future research.

xxi Thanks to Kenji Oda and Manami Hirayama for discussing the Japanese data and to Jaehee Bak for discussing the Korean data. Their intuitions indicate that the most natural word order for these sentences has OV adjacency, but a full investigation into the matter requires further research.

${ }^{x x i i}$ See Lasnik (2001) for arguments that objects in English raise overtly to a low functional projection in the VP domain. See also Johnson (1991).

${ }^{\text {xxiii }} \mathrm{Agr}_{\mathrm{O}} \mathrm{P}$ is null in English, but is possibly overt in Spanish, following Torrego (1998), where it is realized as $a$, and in Romanian, where it is realized as pe on definite/animate objects.

${ }^{x x i v}$ A reviewer asks about the formation of the verbal complex given Pollock (1989) and much subsequent work that verb formation is syntactic. One idea is to relegate this to PF (Boeckx and Stjepanović 2001), but I leave this to future work.

${ }^{\mathrm{xxv}}$ The other VP-fronting analyses referred to above include a VoiceP, which introduces the external argument, in addition to a $v$ P. Closer scrutiny may reveal that such is required for the OVS languages under discussion here, too; however, the analysis presented here does not require a VoiceP, so it is left out.

${ }^{x x v i}$ Assuming a non-lexicalist approach to morpho-syntax the question arises as to how the verbal complex is formed. I tentatively suggest following Boeckx and Stjepanovic (2001) that the verbal complex is formed by head movement PF, but leave the details to future work.

${ }_{\text {xxvii }}$ Absent from this chart is OSV languages. These present a problem for the current approach since they cannot arise by the mechanisms proposed here. This is because the object raises above the subject while the verb remains low. Thus, the object does not raise above the subject by being carried across by the VP. Note this is also a problem for headedness approaches since there is no way to base generate this order with any of the four logically possible settings of such a parameter.

${ }^{x x v i i i}$ It is interesting to note that Kayne (2003, inter alia) has argued that we should abandon the notion that PP is a constituent in the usual sense. While the shorter derivations do suggest this (and it is certainly true in this framework that PPs are not merged as a constituent), the derivation for Hixkaryana in (42) above shows clearly that PPs can become constituents through several applications of remnant movement.

${ }^{x x i x}$ It is unlikely that $\operatorname{Agr}_{S} \mathrm{P}$ is also found in the nominalized clause. The external argument of transitives is Case marked by a postposition and does not trigger agreement on the verb. The external argument of an intransitive, however, does trigger agreement. A thorough examination of the ergative properties of embedded nominalized clauses in Hixkaryana is beyond the scope of this paper.

${ }^{\mathrm{xxx}}$ Evidence that the adjunct DP is selected directly by the verb is furnished by English examples such as the following:

i. $\quad$ I read none of the papers during/before any of lectures.

The adjunct in (9) is clausal in the English translation, but nominal in Hixkaryana (as in the example above). See Barrie (2009) for more details on the English examples. 